\title{
Maestros argentinos: patriotas y nacionalistas. La pedagogía de la patria en las escuelas primarias (1930-1940)
}

\author{
The argentine teachers: patriots and nationalist. The pedagogie of the homeland in \\ primary schools (1930-1940)
}

\author{
Matías Emiliano Casas \\ UNTreF / Université Paris Diderot / CONICET, Buenos Aires, Argentina. mecasas@untref.edu.ar
}

\author{
Fecha de recepción: 7/07/2015. Fechas de reenvíos: 21/04/2016, 27/04/2016. Fecha \\ de aprobación: 20/05/2016. Fecha de publicación: 20/01/2017.
}

\begin{abstract}
Resumen: El sistema escolar argentino estuvo caracterizado, desde sus inicios, por la "imperiosa necesidad" de inculcar sentimientos de patriotismo en sus estudiantes. Un conjunto de ceremonias y efemérides fueron constituyendo los "rituales patrióticos" que se ocupaban, y se ocupan, de exaltar a personajes de la historia y a emblemas de la nación. Este trabajo se concentra en las prescripciones esbozadas para el personal de educación argentino en el contexto del fervor nacionalista que caracterizó la década del treinta. En ese período, la impronta nacionalista -con diversas facetas y manifestaciones- se visualizaba en expresiones políticas, culturales, religiosas y sociales. Para ese estudio, nos concentramos en las publicaciones de las revistas educativas que reprodujeron las normativas e intervinieron en los debates desde sus editoriales. Las recetas patrióticas recuperadas en ese período consolidaron prácticas educativas que se cristalizaron en el sistema escolar argentino.
\end{abstract}

Palabras claves: Educación; identidad nacional; maestros; patriotismo; Argentina.

\begin{abstract}
The Argentinean school system was characterized, since its inception, by a "compelling need"to instill feelings of patriotism in students. A set of ceremonies formed the "patriotic rituals" that exalted, and continue to exalt, historical figures and national symbols. This paper focuses on the requirements outlined for Argentinean educators in the context of the nationalist fervor that characterized the 1930s. Nationalism at that time was displayed in political, cultural, religious and social expressions, with various facets and manifestations. This study was focused on education journals, which reproduced the regulations and intervened in the debates through their editorials. The patriotic prescriptions recovered from that period consolidated educational practices that later crystallized in the Argentinean school system.
\end{abstract}

Keywords: Education; national identity; teachers; patriotism; Argentina. 


\section{La educación patriótica y su historicidad en las políticas educativas argentinas}

El sistema escolar argentino estuvo caracterizado, desde sus inicios, por la"imperiosa necesidad" de inculcar sentimientos de patriotismo en el estudiantado. Un conjunto de ceremonias y efemérides fueron constituyendo los "rituales patrióticos" que se ocupaban, y se ocupan, de exaltar a personajes de la historia y a emblemas de la nación (Amuchastegui, 1995) Este trabajo se concentra en las prescripciones esbozadas para el personal de educación argentino en el contexto de fervor nacionalista que caracterizó la década del treinta. En ese período, la impronta nacionalista -con diversas facetas y manifestaciones- se visualizaba en expresiones políticas, culturales, religiosas y sociales (Devoto, 2005).

El objetivo de este estudio consiste en realizar un análisis de las revistas educativas, las normativas vigentes y las propuestas pedagógicas del período en relación con la promoción del patriotismo en el alumnado de las escuelas primarias. Se considera que durante la década del treinta se visualizó una renovada intensidad en las manifestaciones nacionalistas que atravesaron las prácticas y planificaciones educativas. Al mismo tiempo, ese recorte cronológico se complementa con referencias insoslayables a las reformas implementadas en la primera década del siglo XX, cuando la misión de forjar "patriotas" en la escuela se estructuró a partir de las sanciones del Consejo Nacional de Educación.

Esas reformas, introducidas en el contexto del Centenario de la Revolución de Mayo en 1910, fueron impulsadas por la gestión de José María Ramos Mejía como presidente del Consejo. Además, las modificaciones de los planes educativos se sustentaron en los diagnósticos de Rojas (1922), presentados en La Restauración Nacionalista. Allí se exponía la desconfianza de la intelectualidad de la época en la sociedad cosmopolita que se iba plasmando.' Ramos (1913) había experimentado las consecuencias de ese cosmopolitismo en el ámbito escolar. Las escuelas italianas que adornaban sus paredes con las imágenes de Humberto Primero o docentes que dictaban clases en idiomas extranjeros eran motivaciones que exacerbaban la "urgencia" por la nacionalización del estudiantado.

La puesta en marcha de un aparato ideológico tendiente a consolidar una identidad nacional para la Argentina no era una novedad exclusiva de la generación del Centenario. Como estudia Bertoni (2001), desde finales del siglo XIX se vinculaba a la inmigración como "factor disolvente" de la argentinidad. Ese discurso se reproducía en muchas de las voces políticas más significativas del período. La coyuntura en el cambio de siglo habilitaba las estrategias

$1 \quad$ Ante la incapacidad de los escritores positivistas de forjar una historia escolarizada para cumplir con las funciones educativas de las generaciones futuras, Ricardo Rojas publicó, en 1909, La restauración nacionalista. El escritor santiagueño ocupó puestos claves ligados a las instituciones educativas que le permitieron posicionarse, gracias a los contactos políticos familiares, para ejecutar proyectos en torno a la educación patriótica. En ese libro, que se volvió a editar en 1922, Rojas denunciaba la falta de instrumentos para nacionalizar a los hijos de inmigrantes, promovía la supresión de la escuelas privadas y proponía una reforma en los planes de estudio para, entre otras cosas, incorporar más horas de historia argentina. 
discursivas en pos de establecer sentimientos de pertenencia y referencias identitarias. En esas búsquedas, las apelaciones al pasado como rasgos definidos de lo nacional fueron de los recursos más utilizados.

En las escuelas, el izamiento de la bandera, las conmemoraciones de la Independencia, y el canto del himno, entre otros hábitos, se establecieron como parte constitutiva del tránsito escolar del estudiantado. Ese proceso de "adoctrinamiento nacionalista" se caracterizó por su dogmatismo y se prolongó aun después de la muerte de Ramos Mejía en 1914. Las reformas introducidas en los años del Centenario siguieron vigentes hasta 1939, lo que representaría, para todo el período, una continuidad en cuanto a objetivos pedagógicos y didácticas patrióticas. Ese factor posibilitó que los debates, cuestionamientos y reflexiones sobre la modalidad educativa en Argentina se sucedieran por esos años. El estudio de Escudé (1990), El Fracaso del Proyecto Argentino, demuestra cómo las políticas educativas de Ramos Mejía continuaron vigentes durante las presidencias radicales. Las publicaciones de educación testimoniaban ese carácter patriótico de la escuela: "Todos los pedagogos y sociólogos están conformes en aceptar que, al niño, desde que pisa los umbrales de la escuela, se le debe inculcar un sentimiento nacionalista" (La Obra, 20 de diciembre de 1921, p. 15).

En la década del veinte se fundó la revista La Obra, revista de educación, ciencia y letras. El surgimiento de la publicación se correspondió con una motivación de un grupo de docentes de la Escuela Normal Mariano Acosta de la ciudad de Buenos Aires. En el transcurso de tres décadas, la revista pasó de quinientos ejemplares a producir una tirada de treinta y ocho mil en 1950 (Bernetti, \& Puiggróss, 1993; Ferreyra, 2013; Gvirtz, 1996). Cada número se componía de más de cien páginas que abordaban problemáticas cotidianas del ámbito educativo. De acuerdo con lo planteado por Finocchio (2009), La Obra, que era una publicación no oficial, se ocupó en defender las condiciones labores del personal docente, cuestionando los salarios, los regímenes de licencias, la infraestructura escolar, etc. Además, se dedicó a difundir las experiencias pedagógicas de la Escuela Nueva -que circularían con intensidad en Argentina a partir de la década del veinte(Cucuzza, 2007; Fernández, et 2009; Puiggrós, 1992). En detrimento de la educación positivista, el proceso de enseñanza se centraba en la niñez y se promulgaba la renovación de las prácticas áulicas. Desde esa perspectiva, la revista incluía material didáctico y actividades. La mayoría de sus páginas estaban abocadas a cuestiones ligadas a la profesión docente, desde una perspectiva pedagógica y laboral. A partir de sus editoriales se constataba la pervivencia de la retórica nacionalista que exaltaba el patriotismo como un componente fundamental, no solo para las escuelas sino también para sus maestros y maestras.

\section{"Alma de maestros y alma de patriotas"}

Una editorial publicada en la revista La Obra (1940) daba cuenta de la persistencia del tópico del nacionalismo en la educación. En efecto, en el texto se cuestionaba la "bulla" que iba 
generando la temática por parte de las autoridades educativas y de las publicaciones que reproducían el discurso "patriótico y nacionalista" para las escuelas. Las referencias se dirigían a resoluciones del Consejo Nacional de Educación -organismo dependiente del Ministerio de Justicia e Instrucción Pública que estaba a cargo del político conservador Guillermo Rothe- ${ }^{2}$ que fomentaban la "enseñanza patriótica", proclamándose continuadoras de la orientación ejecutada por Ramos Mejía. En esa publicación se explicitaba: "Quien escuchase, ausente de la realidad... las admoniciones, los temores y los consejos... creería con razón y no sin alarma que en nuestras escuelas nuestros maestros y profesores no cumplen con el deber elemental de suscitar el amor a la patria" (La Obra, 25 de septiembre de 1940, p. 583). Más adelante, atribuyéndose la representación del cuerpo docente, se realizaba un alegato de la tarea diaria abocada a "forjar" los sentimientos de nacionalidad en el alumnado. En el desarrollo del artículo se ponía de relieve ese "deber elemental" que se le adjudicaba no solo a la educación en nivel primario, sino a todas las instancias superiores afirmando: "el magisterio y el profesorado argentinos están exentos de todo cargo en lo que concierne a su fe patriótica" (La Obra, 25 de septiembre de 1940, p. 584).

Las perspectivas para pensar el "deber" patriótico de la educación y la figura de la escuela primaria como "cuna del patriotismo" se reproducían, con las transposiciones didácticas correspondientes, en las revistas educativas.

Otro corpus documental analizado para estudiar esa circulación fue la publicación El Monitor de la Educación Común. La revista era el órgano del Consejo Nacional de Educación y había sido fundada por Domingo Sarmiento en 1881. Desde la sanción de la ley N. ${ }^{\circ} .420$-que en 1884 promulgó la gratuidad y obligatoriedad de la enseñanza- se repartía de modo gratuito en las escuelas. Por ser una publicación destinada al ámbito escolar, sus preocupaciones recaían en las condiciones edilicias, los materiales educativos, el sistema de inspección, etc. A comienzos del siglo XX, sus temáticas principales se centraron en la figura docente. Desde sus páginas comenzaron a difundirse las reglamentaciones, los diseños, informes y actos administrativos que involucraban la formación de los maestros y profesores. Los artículos que se incluían en la revista eran enviados por docentes que colaboraban y respondían a elaboraciones analíticas sobre las prácticas o producciones ensayísticas en diversos temas (Finocchio, 2009).

Desde esa publicación se dirigían una serie de recursos para docentes; se reproducía la perspectiva oficial con respecto a la educación patriótica, que consistía en actividades o materiales para trabajar en el aula. La vicedirectora de una escuela primaria de la Capital Federal, Mattasi (1941), por ejemplo, contribuyó con seis páginas de "postulados patrióticos" para difundir en los espacios educativos. Los mensajes ponderaban, de modo contundente, el

$2 \quad$ Guillermo Rothe era un abogado de la provincia de Córdoba, político del Partido Demócrata Nacional, que ocupó el cargo de Ministro de Justicia e Instrucción Pública hasta el golpe de Estado de 1943. Durante la mayor parte de su ejercicio público, el Consejo Nacional de Educación estuvo a cargo de Pedro Lemitón Ledesma, abogado bonaerense del mismo partido. 
"patriotismo" sobre cualquier virtud y apelaban a cristalizar ese sentimiento, particularmente en la niñez. Así, se proponían frases como: “Desde cualquier lugar puedes y debes proclamar el amor a la patria... jes como tu madre! Si ella desfallece tu [sic] sucumbes." Otras apuntaban a gestar, a partir del patriotismo, actitudes en relación con el proceso de escolarización: "Apoya al buen maestro, él es el 'benemérito de la patria' que se consagra a la superación espiritual del prójimo, olvidado de sí mismo". Además, se recomendaba el estudio de la flora y la fauna para conocer mejor y, de ese modo, "amar más a la tierra". El compendio de postulados concluía, como se hacía explícito en la revista, pretendiendo configurar "cruzados de la argentinidad". El contexto belicoso internacional por el desarrollo de la Segunda Guerra Mundial parecía exacerbar las consideraciones de la vicedirectora que le recomendaba al estudiantado: "prepárate para defenderla [a la patria] de todo peligro" (El Monitor, 30 de septiembre de 1941, pp. 33-38).

Un artículo publicado por La Obra, en 1944, recuperaba el protagonismo de la escuela primaria para fomentar los sentimientos patrióticos y la posicionaba como la institución motora, anteponiéndose al "hogar" y al "medio social". La editorial realizaba una analogía con la vida militar. En ese sentido, se expresaba: "Así como en los cuarteles... se aprende a servir a la patria, en las escuelas se aprende a conocerla y a amarla." En efecto, se reivindicaba la instrucción conceptual sobre esa noción que solo podría otorgarla la escuela primaria. Al profundizar en el concepto, se ponía de relieve una suerte de rechazo al carácter "espontáneo" de ligazón con el terruño y se promovía su educación. En esa línea, se interrogaba en el texto: “Nos conformaríamos con tener una masa ciudadana que sólo por instinto primitivo, casi animal, se sintiese adherida al suelo de la Nación?". La respuesta negativa conllevaba una serie de argumentaciones que pretendía jerarquizar el rol de la escuela para la sociedad (La Obra, 10 de agosto de 1944, p. 383).

\section{Los símbolos patrios en relieve. Medidas, sanciones y prescripciones para los educadores argentinos}

En 1934, el Consejo Nacional de Educación promovió una celebración especial para el Día del Himno, conmemorado el 11 de mayo, que involucraba particularmente al distrito escolar de Vicente López, en la zona norte del Gran Buenos Aires, bautizado en honor del compositor de la "canción patria". ${ }^{3}$ En ese mismo año, una circular de la Inspección General de la Capital advertía a las escuelas de su dependencia: "evitar el uso por alumnos y maestros de todas esas baratijas y colgajos con los que se reemplazan tan a menudo la escarapela nacional". La recomendación se reproducía en la revista La Obra, en cuyas páginas se complementaba la señal de alerta por lo que entendían como una "anarquía en los símbolos patrios". Según la editorial, la representación "incorrecta" de la simbología nacionalista obturaba la eficacia esperada mediante su circulación.

3 Vicente López y Planes fue un escritor y político argentino que se destacó por la composición de la letra del Himno Nacional en 1813. 
Por ese motivo, promovía una especial atención en los docentes en tanto "custodios" de los usos adecuados (La Obra, 25 de julio de 1934).

El gobierno de Manuel Fresco en la provincia de Buenos Aires fue, quizá, el máximo exponente en la reproducción de la narrativa argentinista que ponderaba el cultivo de los símbolos patrios. El médico oriundo de Navarro, municipio del interior, desarrolló su trayectoria política como legislador provincial de 1919 a 1922 y de 1925 a 1931. Además, durante ese año ejerció como comisionado municipal del partido de Morón, donde tenía su residencia y una contundente influencia (Sáez, 2010). Finalmente, desde 1934 hasta los años previos a su gobernación tuvo a su cargo la presidencia de la Cámara de Diputados de la Nación. En las elecciones fraudulentas de 1935, cuando los conservadores debieron competir con los políticos radicales luego de cuatro años de abstención de estos últimos, se proclamó gobernador de Buenos Aires. Fresco fue uno de los máximos exponentes del conservadorismo bonaerense, y manifestó su lema de gobierno con la tríada "Dios, Patria y Hogar".

En una muestra de su recurrente preocupación, un decreto del 17 de junio de 1937, anticipando los preparativos para la conmemoración de la declaración de la independencia, garantizaba la donación de una bandera argentina a cada uno de los 110 distritos escolares que conformaban la provincia de Buenos Aires. La ceremonia de entrega se realizaría en un acto central con la concurrencia de todas las delegaciones a la ciudad de La Plata. En los fundamentos de la medida se manifestaba: "Esta donación constituye un nuevo acto destinado a exaltar el amor a los símbolos patrios y a afirmar el sentimiento nacionalista del magisterio provincial" (Nativa, 30 de junio de 1937, p. 39). Con el objetivo de "avivar el fuego patriótico de los educadores y educandos", Fresco destinaba \$ 60.000 para del proyecto. Algunos historiadores se han detenido en la creación y difusión de los símbolos como herramienta proclive al forjamiento de una identidad cuando los estados-nación debían construir nuevos mecanismos de identificación (Corvalán, 1962; Garavaglia, 2007; Otemberg, 2013). Las sanciones del ámbito educativo y gubernamental, que trascendieron el mandato de Manuel Fresco, recuperaban las proyecciones fundacionales de la simbología nacionalista y pretendían jerarquizar su circulación en las escuelas.

Esa trascendencia quedaba plasmada en la gestión de Roberto Ortiz como máximo mandatario de la nación. En efecto, si bien los lineamientos políticos de su presidencia evidenciaron notorias diferencias con Manuel Fresco -que llevaron a la intervención de la provincia de Buenos Aires y al fin de su gobernación-, las medidas destinadas a la promoción del "patriotismo" se sucedían al margen de las barreras ideológicas. El presidente promulgó en 1938, la ley n 12.361 que instituyó cada 20 de junio como Día de la Bandera en conmemoración del fallecimiento de Manuel Belgrano. La efeméride se declaraba feriado para todas las actividades del país (El Monitor, 1 de junio de 1938). Tres años después, se resolvió celebrar el Día de la Escarapela cada 18 de mayo en todos los distritos escolares de la República. La sanción implicaba la confección y el reparto de la insignia por parte de las alumnas de las escuelas (La Obra, 10 de mayo 
de 1941). Para el cultivo de esos símbolos se le atribuyó al personal docente una particular responsabilidad, no solo como vigías de su utilización y respeto, sino también como modelos en la "veneración" de estos mismos.

Los controles sobre los usos y desusos de los símbolos patrios no se remitieron solo a la provincia de Buenos Aires. En 1939, un diario de la Capital Federal titulaba:"Por no usar la escarapela fue suspendida por 3 meses una maestra rosarina". El Consejo General de Educación había resuelto la suspensión de Ana Calvente de Hembold, maestra de la escuela № 71, porque el 25 de mayo se había negado a colocarse la escarapela argentina. La docente desobedeció a la directora argumentando que no existía una reglamentación en curso sobre su utilización, explicación que no la absolvió del sumario elevado (El Pueblo, 4 de julio de 1939). En efecto, el incidente había ocurrido dos años antes de la resolución que exigía su uso, atenuante que acreditaba la postura de la maestra. La ciudad de Rosario estaba, entonces, bajo la órbita del gobernador Manuel de Iriondo, quien se había desempeñado como Ministro de Justicia e Instrucción Pública de la nación en 1935. El gobernador sostuvo una línea ideológica y política muy emparentada a la experiencia de Fresco en Buenos Aires, en la que el fraude, el intervencionismo, la religión católica y el fervor nacionalista formaban parte de sus ejes centrales.

La práctica punitoria e inquisitoria sobre la reproducción de la iconografía argentinista en las escuelas fue complementada por una operación discursiva de "adoctrinamiento patriótico" que retomó viejas herramientas como la difusión de modelos de clase y enunciaciones que planteaban cierto "temor" por la posible disolución de la identidad nacional.

\section{Modelos de clase y discursos ante el "peligro por los núcleos extranjeros"}

Los esfuerzos por consolidar la "enseñanza patriótica" tendían un puente abstracto con las proclamas de la educación "normalizadora" del Centenario (Eberle, 2012). El relato de la "patria amenazada" se reeditaba en pos de la cristalización de la identidad argentina. Esa operación replicaba en varios libros de texto que focalizaban en el contenido patriótico de sus lecturas. Las narraciones incluidas evidenciaban una continuidad en la denodada búsqueda de representarle, al alumnado de la educación primaria, la figura de la "patria" en términos familiares, trazando analogías con el cariño materno.

Esas intenciones presentaban paralelismos evidentes con las instrucciones delineadas por José María Ramos Mejía en pos de los festejos por los cien años de la Revolución de Mayo. Los modelos de clase difundidos por la publicación del Consejo Nacional de Educación en 1909 contemplaban todos los elementos de la dinámica áulica para construir una atmósfera nacionalista. El autor de esa secuencia era Ernesto Bavio, Inspector Técnico del Consejo. Para la ornamentación de la clase se requería: "una mesa convenientemente arreglada en la tarima que ocupa el frente del salón, aparecen colocados los retratos de San Martín, Moreno, Belgrano y Rivadavia" (El Monitor, 31 de julio de 1908, pp. 1085-1086). 
El diálogo propuesto incluía una serie de interrogantes que pretendían ser contestados al unísono por la totalidad de estudiantes de la clase. La lección estaba pensada para el alumnado de la escuela primaria, pero no se establecía una diferenciación clara por curso, incluso algunas de las expresiones del Inspector permiten suponer que se trataba de una propuesta transversal a todos los años. La maestra comenzaba "explicando": "Sois todavía muy niños para poder comprender de un modo intenso y en todo su alcance lo que significa para nosotros el 25 de Mayo. ¡No importa! Por lo pronto debe bastaros saber que en ese día debéis cantar el Himno con el respeto y unción con que lo acabáis de hacer ahora" (El Monitor, 31.7.1908, pp. 10851086).

El interrogatorio propuesto en la "lección patriótica" de Bavio resulta un ejemplo pertinente de las conceptualizaciones establecidas por el filósofo francés Renan (1987) en orden a los "olvidos y los errores históricos" que evidencian la manipulación del pasado en pos de la construcción de la nación. La maestra preguntaba a los estudiantes:

-¿Qué bandera se enarbola en nuestros edificios públicos, en los cuarteles y en los buques de guerra?

-La Bandera Argentina.

-¿Qué bandera debéis poner el 25 de Mayo en las azoteas, los balcones, o ventanas de vuestras casas?

-La Bandera Argentina.

-¿Qué colores tiene la Bandera Argentina?

-Celeste y blanco.

- Señalar la Bandera Argentina. ¿De dónde son copiados los colores celeste y blanco de la Bandera Argentina?

-Del cielo.

-Sí, mis queridos niños: La Bandera Argentina tiene los colores del cielo y fue inventada en un momento de noble inspiración por el virtuoso patricio, general don Manuel Belgrano. (El Monitor, 31 de julio de 1908, pp. 1085-1086).

En la "interacción" no solo se omitía la relación de los colores con la Real y Distinguida Orden de Carlos III de la Casa Borbónica, sino que se sedimentaba la romántica inspiración en los azules del cielo. El rol docente en la coyuntura del Centenario se centralizaba en la capacidad para transmitir el amor a la patria y promover el culto de la nacionalidad argentina en sus estudiantes. 
Durante la década del treinta, en las escuelas ya no se repudiaba el himno nacional ni se adornaban las paredes con las imágenes de la Reina Margarita, como había observado inquieto Ramos Mejía. Así como las proclamas nacionalistas se actualizaban en pos de captar nuevos interlocutores, la construcción de la "amenaza" foránea también requería nuevos "enemigos" para identificar y, por tanto, "justificar" la reactivación nacionalista.

Los militares que tomaron el mando del Gobierno en el golpe de Estado de 1930 se abocaron, en esos primeros años, a "restituir el orden" intensificando la intervención social. La desarticulación de los sindicatos, la persecución y deportación de comunistas y anarquistas -que en algunos casos incluyó el fusilamiento- reavivaron la animadversión hacia los activistas extranjeros. En los meses sucesivos al golpe se creó, en el seno de la Policía Federal, una Sección Especial de Lucha Contra el Comunismo. Además, en diferentes momentos de la década se aplicó la ley $\mathrm{N}^{\circ}$ 4.144, conocida como la ley de Residencia que había sido promulgada a comienzos del siglo y que permitía expulsar a extranjeros que perturbasen el orden público sin juicio previo (Béjar, 1983; Devoto, 2001).

Desde esa perspectiva, las medidas educativas que pretendían consolidar la identidad nacional, en "permanente peligro de disolución", se sucedieron con frecuencia. En 1940, la impresión de 50.000 ejemplares de la "cartilla patriótica" para ser difundida de manera gratuita en las escuelas del país confirmaba no solo la tarea primaria de los maestros y maestras sino también la función principal de las instituciones educativas. El Consejo Nacional de Educación explicitaba en esa edición una serie de normativas tendientes a fortalecer la instrucción de los "símbolos nacionales" en todos los años de la educación primaria. Además, la cartilla incluía: una descripción de la bandera, el himno y el escudo; la Constitución Nacional; un mapa de la República Argentina; y retratos de José de San Martín y Manuel Belgrano con una breve biografía. La publicación tenía como introducción dos textos sobre patriotismo del escritor Joaquín Víctor González (La Obra, 25 de julio de 1940).

Los modelos de discursos para celebrar las efemérides que circulaban en los años previos a la publicación de la cartilla apelaban también a la interpelación patriótica. El maestro y escritor infantil Germán Berdiales publicó un libro que exponía un conjunto de recursos para implementar en las celebraciones nacionalistas. Su obra titulada Las fiestas de mi escuelita modelaba escenas para el aula y los actos escolares. En el epílogo de su escrito, se incorporaban discursos para que docentes reprodujeran en sus prácticas. El contenido de esos fragmentos se nucleaba en el fomento del nacionalismo y estaba presentado de manera que se pudiese insertar en cualquiera de las efemérides escolares. Los principales destinatarios eran los estudiantes a quienes se los convocaba directamente con expresiones como: "Niños: Nuestra patria es, en verdad, la hija predilecta de los cielos; ellos le dieron su seda y su sol para que los luciese en su bandera; démosle también nosotros la mejor de nuestra alma y consagrémosle nuestra vida" (Berdiales, 1934, p. 205). Alusiones similares a las trazadas para los alumnos y alumnas de las 
escuelas primarias se advertían en los discursos del profesorado Normal 1 enunciados para las futuras maestras. En una conmemoración de la declaración de la independencia se proclamaba la "unidad de todos los argentinos" a partir del núcleo de "una sola religión: la de la patria".

Las propuestas modeladas, fuese por el Consejo o por las iniciativas individuales de educadores o educadoras eran acompañadas por los libros de lectura que incorporaban la "devoción" por la patria. Uno de los autores más reconocidos de los textos escolares fue José Carlos Astolfi, quien había cursado sus estudios de maestro en la Escuela Nacional de Profesores Mariano Acosta de la ciudad de Buenos Aires y se había egresado como profesor en Letras en 1916 en la misma institución. Posteriormente, se integró como miembro a la Academia Nacional de la Historia realizando estudios especializados en la historia argentina, particularmente en la figura de José de San Martín. Astolfi propuso, en una conferencia que fue transcripta por El Monitor de la Educación Común, una pedagogía para la enseñanza patriótica centrada en tres componentes: el culto de los símbolos; la explicación racional del concepto de patria y de su conformación histórica; y el ejemplo personal y la educación moral. Para Astolfi, la tarea de fomentar desde las escuelas la "mística del nacionalismo" constituía una prioridad impostergable en tanto diagnosticaba: "Pese a la admirable fuerza de asimilación de nuestro medio, ciertos núcleos extranjeros se resisten a disolverse en la masa común; semejante oposición engendra un innegable peligro." El "argumento" para legitimar el rebrote nacionalista en la educación de los años treinta presentaba una tónica similar a las reformas implementadas a comienzos de siglo. Como la mencionada iconografía que preocupaba a José María Ramos Mejía, la pervivencia de colectividades de inmigrantes que sostenían el culto de sus tradiciones se reconocía como un factor de peligro en la perspectiva del docente escritor (El Monitor, 30 de junio de 1940).

Esa "amenaza" se reproducía en el ensayo nacionalista de Pablo Pizarro. El autor era un médico cirujano graduado en la Universidad de Córdoba que ejerció en Rosario desde finales de la década del veinte. De acuerdo con los testimonios de sus colegas, no había alcanzado gran reconocimiento en el ámbito de la medicina. En cambio, las tertulias artísticas de las que formaba parte en la capital santafesina le habrían motivado sus intereses ensayísticos. Pizarro se manifestaba como un "simpatizante comunista" y en 1935 viajó a la Unión Soviética para profundizar sus conocimientos en ese sistema. En 1937 se alistó como médico del bando republicano en la guerra civil española. Se desconoce lo que le aconteció durante su estadía en España, pero a su regreso a la Argentina evidenció una mutación rotunda en su ideología. El médico se adhirió a un nacionalismo radicalizado que expuso, de manera contundente, en el libro señalado (Vezzetti, 1996).

La publicación de Afirmación gaucha, en 1943, fue contemporánea a las prescripciones educativas reseñadas. En ese texto, se radicalizaba la oposición a lo foráneo y la sensación de "amenaza". Para contrarrestar "el virus extranjerista (sic)", Pizarro establecía un decálogo con

$4 \quad$ Si bien se corresponde a un período posterior, el discurso en ocasión de la celebración del Día de la Independencia argentina permite advertir la pervivencia de la retórica nacionalista. s/d sobre el autor, 9 de julio de 1950, Archivo de la ENN1, Ciudad Autónoma de Buenos Aires. 
acciones concretas. Imbuido en el espíritu "patriótico" de sus antepasados militares que -según afirmaba en la introducción- habrían combatido a los ejércitos extranjeros por la libertad de la nación-, el autor proponía un combate alternativo pero igual de virulento. La segunda máxima de su decálogo establecía: "Cierre de todas las escuelas, centros políticos, centros culturales, centros deportivos y sociedades mutuales 'extranjeras' o, en el caso, su argentinización inmediata." Las "exigencias" implicaban la prohibición de la enseñanza de idiomas extranjeros en las escuelas y concluía con su premisa más temeraria: "Asimilación urgente, persuasiva $y$, si es necesario, compulsiva y violenta de todos los grupos étnicos 'extranjeros' al Espíritu Nativo y Autónomo de la Nacionalidad tradicional y, en caso contrario, expulsión de los núcleos refractarios fuera del país" (Pizarro, 1943, p. 220-221).

La interpretación de Pablo Pizarro sobre los "peligros" que atentaban contra la identidad nacional coincidía -desde una perspectiva más extremista y radicalizada- con el diagnóstico establecido por el educador José Carlos Astolfi. La fiebre nacionalista que se exacerbaba al calor de las políticas educativas era la variable que consolidaba la liturgia patriótica desde las escuelas primarias.

\section{Consideraciones finales}

Las referencias estudiadas colocaron la pedagogía de la patria en el centro de las funciones escolares. Si bien la centralidad otorgada a las prescripciones nacionalistas no constituyó una novedad absoluta de los años treinta, sí recuperaron su vigor en orden a las políticas implementadas desde el Consejo Nacional de Educación. Esa década constituyó un período de "reafirmación" para las tendencias nacionalistas esbozadas a principios del siglo XX. Como se reseñó en este artículo, muchas de las sanciones que revitalizaban la centralidad de los símbolos patrios en la trayectoria escolar se incorporaron en ese período.

Junto con las efemérides que reforzaban el carácter patriótico de la educación en Argentina, el rol docente fue puesto de relieve desde una perspectiva inquisidora que cuestionaba su filiación nacional. La capacidad para transmitir el "amor a la patria" era uno de los atributos prioritarios para la representación del "buen maestro". Ese fervor nacionalista de los años treinta actualizó la "amenaza permanente" de los componentes extranjeros que, por su activismo político, fueron identificados como posible factores diluyentes de la identidad nacional. Las revistas educativas acompañaron esa preocupación, con variada intensidad. Sus editoriales, la difusión de las normativas y la publicación de textos que enviaban docentes, las configuraron como una fuente insoslayable para analizar esa "cruzada patriótica". Las prescripciones para los educadores y educadoras reprodujeron una perspectiva homogénea y estandarizada para pensar"la patria". Lejos de reivindicar la diversidad étnico-cultural que caracterizaba las diferentes regiones del país o de reflexionar sobre "las patrias" posibles, la coyuntura política determinó un discurso unívoco para la nacionalidad. Los dogmas patrióticos ensayados a comienzos del siglo XX, y recuperados con intensidad en los años aquí estudiados, cristalizaron la base de una 
"pedagogía" que se sedimentó con pujanza en las prácticas educativas argentinas.

De ese modo, se puso de relieve la pervivencia de una"religión cívica". En términos de Mosse (2005), el nacionalismo constituía la máxima expresión de esas "religiones" y se consideraba deudor de un nuevo estilo político decimonónico. La política de masas involucraba un conjunto de ritos y símbolos que conformaban una liturgia patriótica. En Argentina, esa maquinaría perforó los cambios de Gobierno. La reafirmación de las prescripciones educativas forjadas en los primeros años del siglo XX y la imitación de las propuestas pedagógicas, como la cartilla patriótica, durante el período aquí estudiado, corroboraron más continuidades que rupturas. En consonancia con lo planteado por Mosse sobre el carácter "inclusivo" de esa liturgia -en tanto era diseñada con un rol activo asignado para la ciudadana-, hacia principios de la década del cuarenta se incorporarían nuevas referencias para la construcción de la nacionalidad. Los estereotipos del gaucho argentino -y del indio en menor medida- comenzarían a circular con intensidad por las aulas inaugurando una estrategia complementaria en la expansión de la educación patriótica.

\section{Referencias}

Amuchástegui, M. (1995). Los rituales patrióticos en la escuela pública. En A. Puigróss, Discursos pedagógicos e imaginario social en el peronismo (1945-1955). Buenos Aires: Editorial Galerna.

Béjar, M. (1983). Uriburu y Justo: El auge conservador (1930-1935). Buenos Aires: Centro Editor de América Latina.

Berdiales, G. (1934). Las fiestas de mi escuelita. Para la escena y para el aula. Buenos Aires: Kapelusz.

Bernetti, J. y Puigróss, A. (1993). Peronismo: cultura política y educación, 1945-1955. Buenos Aires: Galerna.

Bertoni, L. (2001). Patriotas, cosmopolitas y nacionalistas. La construcción de la nacionalidad argentina a fines del siglo XIX. Buenos Aires: Fondo de Cultura Económica.

Corvalán, D. (1962). Los símbolos patrios. Academia Nacional de la Historia, Historia Argentina. Buenos Aires: El Ateneo.

Cucuzza, H. (2007). Allons enfants de la patrie: el archivo personal de Anunciada Mastelli. Archivo de Ciencias de la Educación (1), 109-130. 
Devoto, F. (2001). El revés de la trama:Políticas migratorias y prácticas administrativas en la Argentina (1919-1949). Desarrollo económico, 41(162).

Devoto, F. (2005). Nacionalismo, fascismo y tradicionalismo en la Argentina moderna. Buenos Aires: Siglo veintiuno editores.

Día de la Escarapela. (10 de mayo de 1941). La obra, p. 375.

Donará una bandera a cada uno de los 110 distritos el doctor Manuel Fresco. (30 de junio de 1937). Nativa, p. 39-40.

Eberle, A. (2012). A la patria los pueblos no la comprenden, la sienten. Análisis historiográfico de la literatura infantil destinada a la escuela oficial primaria argentina, 1884-1930, Madrid: Editorial Académica Española.

El monitor de la educación común. (1 de junio de 1938). Nuevas leyes y decretos, p. 10.

El monitor de la educación común. (30 de junio de 1940). Los maestros y el nacionalismo, p. 116-126.

El monitor de la educación común. (31 de julio de 1908). Cartilla patriótica, p. 1085-1086.

Escudé, C. (1990). El fracaso del proyecto argentino. Buenos Aires: Editorial Tesis.

Fernández, M. et al (2009). Las misiones de divulgación cultural en la experiencia pedagógica de Olga y Leticia Cosettini. Revista de la Escuela de Ciencias de la Educación (4), 67-80.

Ferreyra, G. (2013). La revista La Obra y la política educativa peronista: 1950-1955. Actas de las XIV Jornadas Interescuelas. Universidad Nacional de Cuyo.

Finocchio, S. (2009). La escuela en la historia argentina. Buenos Aires: Edhasa.

Garavaglia, J. (2007). Construir el Estado, inventar la nación: El Rio de la Plata, siglos XVIII-XIX. Buenos Aires: Prometeo, 2007.

Gvirtz, S. (1996). Escuela nueva en Argentina y Brasil: Visiones comparadas. Buenos Aires: Miño y Dávila Editores.

La anarquía de los símbolos patrios. (25 de julio de 1934). La Obra, pp. 425-426.

La escuela en acción. (25 de septiembre de 1940). Educación patriótica y nacionalista. La Obra, p. 
583-584.

La escuela, cuna de patriotismo. (10 de agosto de 1944). La Obra, p. 383.

La orientación nacionalista en nuestro sistema de educación. (20 de diciembre de 1921). La Obra, p. 15-17

La resolución sobre la educación nacionalista. (25 de julio de 1940). La Obra, p. 430-432.

Mattasi, L. (30 de septiembre de 1941). Postulados patrióticos. El monitor de la educación común, p. 33-38.

Mosse, G. (2005). La nacionalización de las masas: Simbolismo político y movimiento de masas en Alemania desde las guerras napoleónicas al Tercer Reich. Madrid: Marcial Pons Historia.

Ortemberg, P. (2013). El origen de las fiestas patrias. Hispanoamérica en la era de las independencias. Rosario: Prohistoria.

Pizarro, P. (1943). Afirmación gaucha. Buenos Aires: Editorial La Facultad.

Por no usar escarapela fue suspendida por tres meses una maestra rosarina. (4 de julio de 1939). El Pueblo, p. 18.

Puiggrós, A. (1992). Escuela, democracia, y orden. Buenos Aires: Galerna.

Ramos Mejía, J. (1913). La educación común en la República Argentina, años 1909-1910, presidencia del doctor don José María Ramos Mejía. Buenos Aires: Talleres Gráficos de la Penitenciaría Nacional.

Renan, E. (1987). ¿Qué es una nación? Carta a Strauss. Madrid: Alianza.

Rojas, R. (1922), La restauración nacionalista: Crítica de la educación argentina y bases para una reforma en el estudio de las humanidades modernas ( 2 da ed.). Buenos Aires: J. Roldán y c. a.

Saez, G. (2010), Morón en la década de 1930. Fresco en la memoria, en E. Reitano, El gobierno de Manuel Fresco en la Provincia de Buenos Aires (1936-1940). La Plata: Instituto Cultural de la Provincia de Buenos Aires.

Vezzetti, H. (1996). Aventuras de Freud en el país de los argentinos, de José Ingenieros a Enrique Pichon-Rivière. Buenos Aires - Barcelona - México: Paidós. 